\title{
HUBUNGAN ANTARA PENDIDIKAN DAN PENGHASILAN DENGAN PENGETAHUAN WANITA USIA SUBUR TENTANG IVA TES
}

\author{
Relationship Between Education And Income With Knowledge Of \\ Fertile Age Women About Iva Tes \\ Lilik Hanifah $^{1}$, Ani Nur Fauziah ${ }^{2}$ \\ STIKES Mamba'ul 'Ulum Surakarta \\ (lilik_hanifah84@yahoo.com)
}

\begin{abstract}
ABSTRAK
Latar Belakang : Pemeriksaan IVA adalah pemeriksaan oleh dokter / bidan atau paramedik terhadap leher rahim yang diberi asam asetat 3-5\% secara inspekulo dengan mata telanjang. Pasien kanker serviks yang datang terlambat ke pelayanan kesehatan masih bisa ditangani, tetapi hanya untuk peningkatan kualitas hidupnya. Kurangnya pengetahuan serta minimnya informasi yang diperoleh mengenai penyakit kanker serviks menyebabkan penderita datang terlambat. Pasien sering merasa takut dan kehilangan semangat hidup ketika mengetahui dirinya menderita penyakit kanker dengan kematian.

Tujuan : Penelitian ini bertujuan untuk mengetahui hubungan antara pendidikan dan penghasilan dengan pengetahuan wanita usia subur tentang iva tes.

Metode : Penelitian ini merupakan penelitian survey analitik dengan pendekatan cross sectional. Populasi penelitian ini adalah seluruh wanita usia subur di Cengklik RT 01 RW 19 Nusukan Banjarsari Surakarta. Subyek penelitian ini seluruh wanita usia subur di Cengklik RT 01 RW 19 Nusukan Banjarsari Surakarta yang berjumlah 33 orang. Pada penelitian ini menggunakan alat pengumpul data berupa kuesioner, jenis kuesioner dalam penelitian ini adalah kuesioner tertutup dengan skala Guttman. Analisa data dalam penelitian ini menggunakan Korelasi Kendall Tau.

Hasil : Karakteristik pendidikan responden mayoritas adalah pendidikan menengah (SMA) yaitu 16 orang $(48,5 \%)$ dan penghasilan responden mayoritas dalam kategori golongan menengah yaitu 19 orang $(57,6 \%)$. Pengetahuan WUS tentang iva tes mayoritas dalam kategori cukup yaitu 13 orang $(39,4 \%)$. Hasil koefisien korelasi Kendall Tau sebesar 0,526 dengan angka signifikan 0,001 sehingga ada hubungan yang signifikan antara Pendidikan dengan Pengetahuan wanita Usia Subur tentang Iva Tes. Hasil koefisien korelasi Kendall Tau sebesar 0,339 dengan angka signifikan 0,034, maka ada hubungan yang signifikan antara Penghasilan dengan Pengetahuan wanita usia subur tentang iva tes
\end{abstract}

Simpulan: Ada hubungan antara pendidikan dan penghasilan dengan pengetahuan wanita usia subur tentang iva tes.

Kata kunci: Pendidikan, Penghasilan, Pengetahuan, Iva Tes. 


\begin{abstract}
Background: IVA examination is an examination by a doctor / midwife or paramedic for the cervix which is given 3-5\% acetic acid inspulatively with the naked eye. Patients with cervical cancer who arrive late to health services can still be treated, but only to improve their quality of life. Lack of knowledge and lack of information obtained regarding cervical cancer causes sufferers to arrive late. Patients often feel afraid and lose the spirit of life when they find out they have cancer with death.
\end{abstract}

The Aim : This study aims to determine the relationship between education and income with knowledge of fertile age woman about test iva.

Method: This study is an analytical survey research with a cross sectional approach. The population of this study were all women of childbearing age in Cengklik RT 01 RW 19 Nusukan Banjarsari Surakarta. The subjects of this study were all women of childbearing age in Cengklik RT 01 RW 19 Nusukan Banjarsari Surakarta, totaling 33 people. In this study using a data collection tool in the form of a questionnaire, the type of questionnaire in this study was a closed questionnaire with Guttman scale. Analysis of data in this study using Correlation Kendall Tau.

Result: The education characteristics of the majority of respondents are secondary education (SMA) which is 16 people (48.5\%) and the income of the majority of respondents in the Middle Group category is 19 people (57.6\%). WUS's knowledge of the majority of test iva in the adequate category was 13 people (39.4\%). The results of the Kendall Tau correlation coefficient are 0.526 with a significant number of 0.001 so there is a significant relationship between Education and Knowledge of Fertile Ages about Iva Tests. The results of the Kendall Tau correlation coefficient of 0.339 with a significant number of 0.034, then there is a significant relationship between income and knowledge of fertile Age women about Iva Tes

Conclusion: There is a relationship between education and income with knowledge of women of childbearing age about test iva.

Key words: Education, Income, Knowledge, Iva Test.

\title{
PENDAHULUAN
}

Kanker serviks merupakan suatu keganasan yang disebabkan oleh adanya pertumbuhan sel-sel epitel serviks yang tidak terkontrol. Berdasarkan data dari World Health Organization (WHO) pada tahun 2012, kanker serviks merupakan jenis kanker keempat yang paling sering ditemukan pada wanita. Sebanyak 528.000 kasus baru dan 266.000 kematian ditemukan di seluruh dunia dan lebih dari $85 \%$ berasal dari negara berkembang termasuk Indonesia (WHO, 2013). Kanker serviks menempati urutan kedua setelah kanker payudara sebagai kanker yang paling sering diderita wanita Indonesia. Data dari GLOBOCAN 
menunjukkan bahwa terdapat 20.928 kasus baru dan 9.928 kematian ditemukan di Indonesia pada tahun 2012 (GLOBOCAN, 2012)

Program deteksi dini kanker serviks sampai tahun 2014 telah berjalan pada 1.986 Puskesmas di 304 kabupaten/kota yang berada di 34 provinsi di Indonesia. Sedangkan untuk cakupan dan hasil skrining telah dilakukan terhadap 904.099 orang $(2,45 \%)$, angka tersebut masih rendah sehingga memerlukan upaya lebih kuat untuk mencapai target yaitu 50\% perempuan usia 30-50 tahun selama 5 tahun. Untuk meningkatkan pelaksanaan pencegahan dan deteksi dini kanker pada perempuan di Indonesia, pemerintah melakukan optimalisasi program deteksi dini kanker serviks untuk periode 2015-2019. Upaya yang dilakukan adalah gerakan deteksi dini melalui metode pemeriksaan IVA secara serentak di seluruh wilayah Indonesia pada 21 April 2015. Gerakan ini akan berlangsung selama 5 tahun dan diharapkan pada tahun 2019 jumlah WUS (wanita usia subur) yang dilakukan deteksi dini mencapai 50 persen. (Kemenkes RI, 2015).

Menurut Profil Kesehatan Provinsi Jawa Tengah tahun 2015, jumlah WUS yang dilakukan deteksi dini IVA di Jawa Tengah tahun 2015 yang dilaporkan sebanyak 18.954 WUS atau 0,30 persen. Persentase WUS ini masih sangat jauh dari target yang ditetapkan sebesar 10 persen. Jumlah 18.954 WUS yang dilakukan IVA test, ditemukan IVA positif pada 1.868 WUS atau 9,86 persen, angka ini lebih tinggi dari yang ditetapkan oleh kementerian kesehatan yaitu 3 persen (Dinkes Prov Jateng, 2015).

Dewasa ini sudah dikenal beberapa metode deteksi dini kanker serviks yaitu tes pap smear, IVA, pembesaran IVA dengan gineskopi, kolkoskopi, servikografi, thin prep dan tes HPV. Namun yang sesuai dengan kondisi di negara berkembang termasuk Indonesia adalah dengan menggunakan metode IVA, karena tekniknya mudah dan sederhana, biayanya murah, tingkat sensitifitasnya tinggi, cepat serta cukup akurat untuk menemukan kelainan pada tahap kelainan sel (Displasia) atau sebelum pra kanker. Namun, kurangnya kesadaran dari wanita usia subur untuk melakukan deteksi dini kanker serviks menjadikan pemeriksaan IVA ini kurang diminati(Fauziah, 2011: 448).

Pemeriksaan IVA adalah pemeriksaan oleh dokter / bidan atau paramedik terhadap leher rahim yang diberi asam asetat 3-5\% secara inspekulo dengan mata telanjang. Lesi prakanker jaringan ektoserviks rahim yang diolesi asam asetat (asam cuka) akan berubah warna menjadi putih (acetowhite). Namun bila ditemukan lesi makroskopis yang dicurigai kanker, pengolesan asam asetat tidak dilakukan dan pasien segera dirujuk ke sarana yang lebih lengkap (Sulistiowati, 2014:194).

Pasien kanker serviks yang datang terlambat ke pelayanan kesehatan masih bisa ditangani, tetapi hanya untuk peningkatan kualitas hidupnya. Kurangnya pengetahuan serta minimnya informasi yang diperoleh mengenai penyakit kanker serviks menyebabkan penderita datang terlambat. Pasien sering merasa takut dan kehilangan semangat hidup ketika mengetahui dirinya menderita penyakit kanker dengan kematian (Widiastuti, 2009)

Belum tercapainya target pemeriksaan IVA disebabkan oleh kurangnya pengetahuan wanita tentang kanker serviks dan rendahnya kesadaran wanita untuk mengikuti deteksi dini. Pengetahuan yang baik tentang kanker serviks diharapkan 
dapat mendorong wanita tersebut untuk melakukan pencegahan sedini mungkin. Dimana salah satu faktor yang mempengaruhi pengetahuan adalah pendidikan. Hal ini didukung oleh penelitian dengan hasil untuk variable independent pendidikan diperoleh nilai sig 2 tailed $(\mathrm{p})=0,000$ dimana $\mathrm{p}<0,05$ maka $\mathrm{H} 0$ ditolak , artinya Ada Hubungan antara Pendidikan dengan Pelaksanaan Deteksi Dini Kanker Servik melalui IVA. Dari hasil penelitian disarankan, Peningkatan Pengetahuan melalui PKK, Sosialisasi, atau Penyuluhan Kesehatan (Mimatun, 2013).

Selain pendidikan, faktor yang yang berhubungan dengan pengetahuan seseorang adalah penghasilan atau sosial ekonomi, yang didukung oleh penelitian dengan hasil Hubungan yang paling dominan pada kanker leher rahim dengan deteksi dini kanker leher rahim di wilayah kecamatan Gisting kabupaten Tanggamus Lampung tahun 2016 adalah status ekonomi dengan $p$-value $<0,001$; OR 6,8. Disarankan bagi puskesmas Gisting untuk menyosialisasikan pemeriksaan IVA dan Papsmaer gratis bagi peserta BPJS dan lebih meningkatkan kegiatan sosial dengan pemeriksaan IVA gratis bagi masyarakat serta lebih meningkatkan penyuluhan kepada masyarakat sehingga timbul kepercayaan masyarakat agar mau melakukan pemeriksaan IVA dan papsmear dengan menghadirkan teman atau kerabat yang sudah pernah melakukan deteksi dini dengan IVA maupun papsmear (Christin, 2016).

Berdasarkan latar belakang di atas, penulis tertarik untuk melakukan penelitian tentang "Hubungan Antara Pendidikan dan Penghasilan dengan Pengetahuan Wanita Usia Subur Tentang Iva Tes," sehingga dapat meningkatkan pengetahuan wanita usia subur tentang iva tes sebagai upaya deteksi dini kanker serviks.

\section{METODE PENELITIAN}

Penelitian ini merupakan penelitian survey analitik dengan pendekatan cross sectional. Populasi penelitian ini adalah seluruh wanita usia subur di Cengklik RT 01 RW 19 Nusukan Banjarsari Surakarta. Subyek penelitian ini seluruh wanita usia subur di Cengklik RT 01 RW 19 Nusukan Banjarsari Surakarta yang berjumlah 33 orang.

Pada penelitian ini menggunakan alat pengumpul data berupa kuesioner, jenis kuesioner dalam penelitian ini adalah kuesioner tertutup dengan skala Guttman. Metode pengumpulan data yang digunakan adalah pengumpulan data primer dan sekunder. Dalam penelitian ini pengumpulan data primer dilakukan dengan membagikan kuesioner secara langsung kepada wanita usia subur, sedangkan pengumpulan data sekunder dilakukan dengan cara melihat dokumen-dokumen atau catatan-catatan yang mendukung data penelitian. Analisa data dalam penelitian ini menggunakan Korelasi Kendall Tau. 


\section{HASIL DAN PEMBAHASAN}

Tabel 1 Distribusi Frekwensi Karakteristik Responden Berdasarkan Pendidikan dan Penghasilan

\begin{tabular}{lcc}
\hline \multicolumn{1}{c}{ Karakteristik } & Frekwensi (f) & Prosentase (\%) \\
\hline Pendidikan & & \\
Pendidikan Dasar (SD, SMP) & 8 & 24,2 \\
Pendidikan Menengah (SMA) & 16 & 48,5 \\
Pendidikan Tinggi (PT) & 9 & 27,3 \\
Total & 33 & 100 \\
Penghasilan & 7 & \\
Golongan Bawah (<1.500.000/bulan) & 19 & 21,2 \\
Golongan Menengah (1.500.000 - 2.500.000/bulan) & 7 & 57,6 \\
Golongan Atas (2.500.000 - 3.500.000/bulan) & 33 & 21,2 \\
Total & & 100 \\
\hline
\end{tabular}

Berdasarkan Tabel 1. menunjukkan karakteristik pendidikan responden, mayoritas adalah pendidikan menengah (SMA) yaitu 16 orang (48,5\%), penghasilan responden mayoritas dalam kategori golongan menengah yaitu 19 orang $(57,6 \%)$

Tabel 2 Distribusi Frekuensi Variabel Pengetahuan Wanita Usia Subur Tentang Iva Tes

\begin{tabular}{ccc}
\hline Pengetahuan & Frekuensi (f) & Prosentase (\%) \\
\hline Kurang & 10 & 30,3 \\
Cukup & 13 & 39,4 \\
Baik & 10 & 30,3 \\
Total $(\mathrm{n})$ & 33 & 100 \\
\hline
\end{tabular}

Tabel 2 diatas menunjukkan bahwa pengetahuan WUS tentang iva tes mayoritas dalam kategori cukup yaitu 13 orang $(39,4 \%)$

Tabel 3 Hubungan Pendidikan dan Pengetahuan wanita Usia Subur tentang Iva Tes

\begin{tabular}{|c|c|c|c|c|c|c|c|c|c|}
\hline \multicolumn{2}{|c|}{ Pengetahuan } & \multicolumn{6}{|c|}{ Pendidikan } & \multirow[t]{2}{*}{ Total } & \multirow[t]{2}{*}{$(\%)$} \\
\hline & & \multirow{2}{*}{$\frac{\text { Dasar }}{6}$} & \multirow{2}{*}{$\begin{array}{l}\%) \\
60\end{array}$} & \multirow{2}{*}{$\begin{array}{c}\text { Mene } \\
\text { ngah }\end{array}$} & \multirow{2}{*}{$\begin{array}{l}\%) \\
20\end{array}$} & \multirow{2}{*}{$\frac{\text { Tinggi }}{2}$} & \multirow{2}{*}{$\begin{array}{l}\%) \\
20\end{array}$} & & \\
\hline Kurang & $(\%)$ & & & & & & & 10 & 30,3 \\
\hline Cukup & $(\%)$ & 1 & 7,7 & 12 & 92,3 & 0 & 0 & 13 & 39,4 \\
\hline Baik & $(\%)$ & 1 & 10 & 2 & 20 & 7 & 70 & 10 & 30,3 \\
\hline Total & & 8 & 21,2 & 16 & 57,6 & 9 & 27,3 & 33 & 100 \\
\hline
\end{tabular}

Berdasarkan tabel 3 diketahui bahwa responden yang memiliki pengetahuan kurang mayoritas pada pendidikan dasar yaitu 6 orang $(60 \%)$, pengetahuan cukup mayoritas pada pendidikan menengah yaitu 12 orang $(92,3 \%)$, pengetahuan baik mayoritas pada pendidikan tinggi yaitu 7 orang $(70 \%)$. 
Tabel 4 Hubungan Penghasilan dan Pengetahuan wanita Usia Subur tentang Iva Tes

\begin{tabular}{|c|c|c|c|c|c|c|c|c|c|}
\hline \multicolumn{2}{|c|}{ Pengetahuan } & \multicolumn{6}{|c|}{ Penghasilan } & \multirow[t]{2}{*}{ Total } & \multirow[t]{2}{*}{$(\%)$} \\
\hline & & Bawah & $(\%)$ & $\begin{array}{l}\text { Mene } \\
\text { ngah }\end{array}$ & $(\%)$ & Atas & $(\%)$ & & \\
\hline Kurang & $(\%)$ & 5 & 50 & 3 & 30 & 2 & 20 & 10 & 30,3 \\
\hline Cukup & $(\%)$ & 1 & 7,7 & 11 & 84,6 & 1 & 7,7 & 13 & 39,4 \\
\hline Baik & $(\%)$ & 1 & 10 & 5 & 50 & 4 & 40 & 10 & 30,3 \\
\hline Total & & 7 & 24,2 & 19 & 48,5 & 7 & 21,2 & 33 & 100 \\
\hline
\end{tabular}

Berdasarkan tabel 4 diketahui bahwa responden yang memiliki pengetahuan kurang mayoritas pada penghasilan bawah yaitu 5 orang $(50 \%)$, pengetahuan cukup mayoritas pada penghasilan menengah yaitu 11 orang $(84,6 \%)$, pengetahuan baik mayoritas pada penghasilan menengah yaitu 5 orang $(50 \%)$.

Tabel 5 Analisa Bivariat Kendall Tau Hubungan Pendidikan dengan Pengetahuan Wanita Usia Subur tentang Iva Tes

\section{Correlations}

\begin{tabular}{lllcc} 
& & Pendidikan & Pengetahuan \\
\hline Kendall's tau_b & Pendidikan & Correlation Coefficient & 1.000 & $.526^{*}$ \\
& & Sig. (2-tailed) &. & .001 \\
& & $\mathrm{~N}$ & 33 & 33 \\
& \multirow{2}{*}{ Pengetahuan } & Correlation Coefficient & $.526^{*}$ & 1.000 \\
& & Sig. (2-tailed) & .001 &. \\
& $\mathrm{~N}$ & 33 & 33 \\
\hline
\end{tabular}

**. Correlation is significant at the 0.05 level (2-tailed).

Berdasarkan tabel 5 diketahui hasil koefisien korelasi Kendall Tau sebesar 0,526 dengan angka signifikan 0,001. Karena $\mathrm{N}>30$ maka signifikansi menggunakan $\mathrm{Z}$ tabel. Penelitian ini menggunakan Uji 2 sisi dengan $\alpha=5 \%$ maka $\alpha=5 \%=0,05: 2=0,025$. Sehingga pada tabel ditemukan nilai $Z=1,96$. Karena $\mathrm{Z}$ hitung $(3,32)>\mathrm{Ztabel}(1,96)$ maka $\mathrm{H}_{0}$ ditolak dan $\mathrm{H}_{\mathrm{a}}$ diterima jadi ada hubungan yang signifikan antara Pendidikan dan dengan Pengetahuan wanita Usia Subur tentang Iva Tes

Tabel 6 Analisa Bivariat Kendall Tau Hubungan Penghasilan dengan Pengetahuan wanita Usia Subur tentang Iva Tes

\begin{tabular}{lllcc}
\hline & & & \\
& & & \\
\hline Kendall's tau_b & Penghasilan & Correlation Coefficient & 1.000 & $.339^{*}$ \\
& & Sig. (2-tailed) &. & .034 \\
& & N & 33 & 33 \\
& \multirow{2}{*}{ Pengetahuan } & Correlation Coefficient & $.339^{*}$ & 1.000 \\
& & Sig. (2-tailed) & .034 &. \\
& & N & 33 & 33 \\
\hline
\end{tabular}




\begin{tabular}{lllcc}
\hline & & & \\
& & & \\
& & & \\
Kendall's tau_b & Penghasilan & Correlation Coefficient & 1.000 & $.339^{*}$ \\
& & Sig. (2-tailed) &. & .034 \\
& & $\mathrm{~N}$ & 33 & 33 \\
& \multirow{2}{*}{ Pengetahuan } & Correlation Coefficient & $.339^{*}$ & 1.000 \\
& & Sig. (2-tailed) & .034 &. \\
& $\mathrm{~N}$ & 33 & 33 \\
\hline **. Correlation is significant at the 0.05 level (2-tailed) & &
\end{tabular}

Berdasarkan tabel 6 diketahui hasil koefisien korelasi Kendall Tau sebesar 0,339 dengan angka signifikan 0,034. Karena $\mathrm{N}>30$ maka signifikansi menggunakan $\mathrm{Z}$ tabel. Penelitian ini menggunakan Uji 2 sisi dengan $\alpha=5 \%$ maka $\alpha=5 \%=0,05: 2=0,025$. Sehingga pada tabel ditemukan nilai $Z=1,96$. Karena $\mathrm{Z}$ hitung $(3,32)>\mathrm{Ztabel}(1,96)$ maka $\mathrm{H}_{0}$ ditolak dan $\mathrm{H}_{\mathrm{a}}$ diterima jadi ada hubungan yang signifikan antara Penghasilan dengan Pengetahuan wanita Usia Subur tentang Iva Tes

Berdasarkan Tabel 1. dapat dilihat bahwa menurut karakteristik pendidikan responden, mayoritas adalah pendidikan menengah (SMA) dan penghasilan responden mayoritas dalam kategori Golongan Menengah. Pengetahuan dipengaruhi beberapa faktor diantaranya adalah pendidikan Pendidikan merupakan suatu proses terhadap anak didik berlangsung terus sampai anak mencapai dewasa susila. Pendidikan tinggi yang dimiliki seseorang akan menyebabkan lebih mudah menerima informasi sehingga pengetahuannya bertambah. Sebaliknya pendidikan yang rendah akan menghambat perkembangan sikap seseorang terhadap nilai- nilai yang baru diperkenalkan (Wawan, 2011). Penghasilan atau tingkat pendapatan seseorang juga akan menentukan tersedianya suatu fasilitas yang diperlukan untuk kegiatan tertentu, sehingga tingkat pendapatan ini akan mempengaruhi pengetahuan seseorang. (Oktarisa, 2016)

Tabel 2. Menunjukkan pengetahuan WUS mayoritas adalah cukup. Pengetahuan WUS dalam kategori baik, cukup, maupun kurang dikarenakan ada beberapa faktor yang mempengaruhi pengetahuan seperti faktor internal yaitu kesehatan jasmani dan rohani seseorang, termasuk didalamnya adalah kesehatan indera, kesehatan psikis, intelektual, psikomotor, serta kondisi afektif dan kognitif seseorang. Selain itu juga dipengaruhi dari faktor eksternal yang meliputi pendidikan, paparan media masa, ekonomi, hubungan sosial, pengalaman, pekerjaan, umur, lingkungan, dan intelegensi (Wawan, 2011).

Tabel 3 menunjukkan bahwa responden yang memiliki pengetahuan kurang mayoritas pada pendidikan dasar pengetahuan cukup mayoritas pada pendidikan menengah dan pengetahuan baik mayoritas pada pendidikan tinggi. Tingkat pendidikan seseorang akan berpengaruh dalam memberi respon terhadap sesuatu yang datang dari luar. Orang yang berpendidikan tinggi akan memberi respon yang lebih rasional terhadap informasi yang datang dan akan berfikir sejauh mana keuntungan yang mungkin akan mereka peroleh dari gagasan tersebut (Wawan, 2011). Semakin tinggi tingkat pendidikan seseorang akan 
semakin luas pengetahuannnya. Semakin tinggi pengetahuan dan pemahaman terhadap kesehatan, akan meningkatkan pula cara pandang terhadap konsep sehat dan sakit menjadi mantap yang pada akhirnya akan mempengaruhi pandangan, cara hidup dan upaya seseorang untuk dapat meningkatkan derajat kesehatan (Setiyowati, 2011).

Berdasarkan tabel 4 diketahui bahwa responden yang memiliki pengetahuan kurang mayoritas pada penghasilan bawah, pengetahuan cukup mayoritas pada penghasilan menengah dan pengetahuan baik mayoritas pada penghasilan menengah. Status sosial ekonomi adalah kedudukan atau posisi seseorang dalam masyarakat. Status sosial ekonomi adalah gambaran tentang keadaan seseorang atau suatu masyarakat yang ditinjau dari segi sosial ekonomi, gambaran itu seperti tingkat pendidikan, pendapatan dan sebagainya. Status ekonomi kemungkinan besar merupakan pembentuk gaya hidup keluarga. Pendapatan keluarga memadai akan menunjang pengetahuan seseorang. Status sosial ekonomi yang yang baik akan sangat mendukung kehidupan seseorang atau keluarga untuk menerapkan kehidupan yang lebih baik, dimana status soaial ekonomi yang baik maka akan menunjang pengetahuan sesorang menjadi baik pula, sedangkan penghasilan yang kurang maka akan mengakibatkan pengetahuan sesorang menjadi kurang (Fariza, 2013)

Tabel 5 menunjukkan hasil koefisien korelasi Kendall Tau sebesar 0,526 dengan angka signifikan 0,001. Karena $\mathrm{N}>30$ maka signifikansi menggunakan $\mathrm{Z}$ tabel. Penelitian ini menggunakan Uji 2 sisi dengan $\alpha=5 \%$ maka $\alpha=5 \%=0,05$ : $2=0,025$. Sehingga pada tabel ditemukan nilai $Z=1,96$. Karena $Z$ hitung $(3,32)>$ Ztabel $(1,96)$ maka $\mathrm{H}_{0}$ ditolak dan $\mathrm{H}_{\mathrm{a}}$ diterima jadi ada hubungan yang signifikan antara Pendidikan dan dengan Pengetahuan wanita Usia Subur tentang Iva Tes

Pengetahuan atau kognitif merupakan domain yang sangat penting untuk terbentuknya tindakan seseorang (over behavior). Berdasarkan pengalaman dan penelitian perilaku yang didasari oleh pengetahuan akan langgeng dibandingkan perilaku yang tidak didasari oleh pengetahuan. Pengetahuan dipengaruhui beberapa faktor diantaranya adalah pendidikan. Pendidikan tinggi yang dimiliki seseorang akan menyebabkan lebih mudah menerima informasi sehingga pengetahuannya bertambah. Sebaliknya pendidikan yang rendah akan menghambat perkembangan sikap seseorang terhadap nilai- nilai yang baru diperkenalkan. Dengan pendidikan yang tinggi seseorang dapat memiliki pengetahuan tentang iva tes dengan baik, begitu pula sebaliknya rendahnya tingkat pendidikan seseorang maka pengetahuan tentang iva tes kurang (Wawan, 2011)

Hasil penelitian didukung oleh penelitian dengan hasil bahwa sebanyak 19,4 \% berpendidikan SMA dan memiliki pengetahuan cukup 52,8 \% tentang pap smear dengan uji statistik menunjukkan bahwa terdapat hubungan antara tingkat pendidikan $(\rho$ Value $=0,000)$ dengan pengetahuan tentang pap smear. Semakin tinggi pendidikan semakin baik cara menerima informasi sehingga banyak informasi yang didapat. Pengetahuan baik yang dimiliki oleh wanita usia subur didapatkan melalui interaksi sosial dengan berbagi pengalaman dengan mereka yang pernah melakukan pap smear.Kesimpulan :Persepsi yang baik tentang 
pencegahan kanker leher rahim berhubungan dengan tindakan pencegahan dengan deteksi dini kanker leher rahim dengan pap smear (Erika, 2018)

Penelitian ini juga sejalan dengan penelitian dimana hasil Uji statistik menunjukan hasil $\mathrm{x}^{2}$ sebesar 11,480 $\mathrm{x}^{2}$ tabel 9,49 dengan nilai P 0,05. Hal tersebut menunjukan bahwa hasil penelitian significan. Dari penelitian tersebut dapat disimpulkan bahwa ada pengaruh antara tingkat pendidikan formal dengan pengetahuan mengenai SADARI. Pengaruhnya sendiri yaitu semakin tinggi tingkat pendidikan maka semakin tinggi pula tingkat pengetahuan seseorang yang dalam hal ini wanita usia subur mengenai SADARI (Rini, 2010)

Penelitian yang mendukung berikutnya yaitu dengan hasil distribusi tingkat pendidikan di desa Kauman sebagian besar berpendidikan akhir SMA yaitu sebanyak 19 responden (50\%). Tingkat pengetahuan ibu rumah tangga tentang Pap smear sebagian besar dalam kategori cukup baik yaitu sebanyak 18 responden (47\%). Hasil analisis hubungan tingkat pendidikan dengan pengetahuan ibu rumah tangga tentang Pap smear diperoleh nilai (+) 0,038 yang berarti nilai $\mathrm{p}<0,05$. Kesimpulan : Terdapat hubungan yang signifikan antara tingkat pendidikan dengan pengetahuan ibu rumah tangga tentang Pap smear di Desa Kauman Kecamatan Tangen Kabupaten Sragen (Pristihana, 2013)

Pada tabel 6 diketahui hasil koefisien korelasi Kendall Tau sebesar 0,339 dengan angka signifikan 0,034. Karena $\mathrm{N}>30$ maka signifikansi menggunakan $\mathrm{Z}$ tabel. Penelitian ini menggunakan Uji 2 sisi dengan $\alpha=5 \%$ maka $\alpha=5 \%=0,05$ : $2=0,025$. Sehingga pada tabel ditemukan nilai $Z=1,96$. Karena $Z$ hitung $(3,32)>$ Ztabel $(1,96)$ maka $\mathrm{H}_{0}$ ditolak dan $\mathrm{H}_{\mathrm{a}}$ diterima jadi ada hubungan yang signifikan antara Pendidikan dan Pengetahuan wanita Usia Subur tentang Iva Tes.

Status sosial ekonomi adalah kedudukan atau posisi seseorang dalam masyarakat. Status sosial ekonomi adalah gambaran tentang keadaan seseorang atau suatu masyarakat yang ditinjau dari segi sosial ekonomi, gambaran itu seperti tingkat pendidikan, pendapatan dan sebagainya. Status ekonomi kemungkinan besar merupakan pembentuk gaya hidup keluarga. Pendapatan keluarga memadai akan menunjang pengetahuan seseorang. Status sosial ekonomi yang yang baik akan sangat mendukung kehidupan seseorang atau keluarga untuk menerapkan kehidupan yang lebih baik, dimana status soaial ekonomi yang baik maka akan menunjang pengetahuan sesorang menjadi baik pula, sedangkan penghasilan yang kurang maka akan mengakibatkan pengetahuan sesorang menjadi kurang (Fariza, 2013)

Penelitian ini didukung oleh penelitian lain yaitu Selain pendidikan, faktor yang yang berhubungan dengan pengetahuan seseorang adalah penghasilan atau sosial ekonomi, yang didukung oleh penelitian dengan hasil Hubungan yang paling dominan pada kanker leher rahim dengan deteksi dini kanker leher rahim di wilayah kecamatan Gisting kabupaten Tanggamus Lampung tahun2016 adalah status ekonomi dengan p-value < 0,001; OR 6,8. Disarankan bagi puskesmas Gisting untuk menyosialisasikan pemeriksaan IVA dan Papsmaer gratis bagi peserta BPJS dan lebih meningkatkan kegiatan sosial dengan pemeriksaan IVA gratis bagi masyarakat serta lebih meningkatkan penyuluhan kepada masyarakat sehingga timbul kepercayaan masyarakat agar mau melakukan pemeriksaan IVA 
dan papsmear dengan menghadirkan teman atau kerabat yang sudah pernah melakukan deteksi dini dengan IVA maupun papsmear (Christin, 2016).

Penelitian lain menyatakan Pengetahuan mengenai TB yang tinggi berhubungan dengan status ibu yang tidak bekerja ( $\mathrm{p}=0,004$ RP 0,894 IK95\% 0,83;0,97),penghasilan keluarga yang tinggi ( $\mathrm{p}<0,001 \mathrm{RP} 1,33$ IK95\% 1,12;1,15), pendidikan terakhir yang tinggi ( $\mathrm{p}<0,001 \mathrm{RP} 1,41 \mathrm{IK} 95 \%$ 1,31; 1,51), dan mendapatkan informasi ( $\mathrm{p}<0,001$ RP 0,082 IK95\% 0,037; 0,178). Pengetahuan yang benar mengenai TB masih rendah dan televisi berperan besar dalam meningkatkan pengetahuan mengenai TB pada ibu di Jakarta Timur. Disimpulkan pengetahuan mengenai TB berhubungan dengan faktor-faktor sosio ekonomik ibu dan dapat ditingkatkan dengan sumber informasi yang tepat (Harris, 2015)

\section{SIMPULAN DAN SARAN}

\section{Simpulan}

Karakteristik pendidikan responden mayoritas adalah pendidikan menengah (SMA) yaitu 16 orang $(48,5 \%)$ dan penghasilan responden mayoritas dalam kategori Golongan Menengah yaitu 19 orang (57,6\%). Pengetahuan WUS tentang iva tes mayoritas dalam kategori cukup yaitu 13 orang $(39,4 \%)$. Hasil koefisien korelasi Kendall Tau sebesar 0,526 dengan angka signifikan 0,001 sehingga ada hubungan yang signifikan antara Pendidikan dan dengan Pengetahuan wanita Usia Subur tentang Iva Tes. Hasil koefisien korelasi Kendall Tau sebesar 0,339 dengan angka signifikan 0,034. maka ada hubungan yang signifikan antara Penghasilan dengan Pengetahuan wanita Usia Subur tentang Iva Tes

\section{Saran}

Bagi wanita usia subur dari hasil penelitian ini diharapkan untuk meningkatkan pengetahuan tentang iva tes melalui media masa, baik surat kabar, majalah, sosial media dan tenaga kesehatan sehingga selain pengetahuan tentang iva tesnya meningkat juga dapat meningkatkan keikutsertaan iva tes sebagai upaya deteksi dini kanker serviks. Bagi Tenaga Kesehatan diharapkan dapat berkerja sama dengan intitusi pendidikan guna memberikan penyuluhan kesehatan secara rutin kepada masyarakat khususnya tentang iva tes.

\section{DAFTAR PUSTAKA}

Christin.A.F, 2016. Faktor-Faktor yang Berhubungan dengan Deteksi Dini Kanker Leher Rahim di Kecamatan Gisting Kabupaten Tanggamus Lampung. Jurnal Kesehatan Politeknik Kesehatan Kementrian Kesehatan Tanjung Karang. Vol 7 No 2 (2016)

Dinas kesehatan Provinsi Jawa Tengah. 2015. Profil Kesehatan Provinsi Jawa tengah Tahun 2015. Jawa Tengah:Dinkes Provinsi Jawa Tengah 
Erika Martiningwardani, Eppysetiyowati. 2018. Hubungan Pendidikan Dengan Pengetahuan Wanita Usia Subur Tentang Pap Smear Di Pondok Pesantren Al Hidayah Kendal Ngawi. Jurnal Ilmiah Kesehatan, Vol 13. No 1. Februari 2018, Hal 92-96

Fariza. A. 2013. Hubungan Status Gizi Dengan Tingkat Sosial Ekonomi Orang Tua / Wali Murid Siswa Kelas Atas Sekolah Dasar Negeri 3 Jatiluhur Kecamatan Karanganyar Kabupaten Kebumen. Skripsi Fakultas Ilmu Keolahragaan Universitas Negeri Yogyakarta

Fauziah, Ratri Manjari. 2011. Deteksi Dini Kanker Serviks pada Pusat Pelayanan Primer di Lima Wilayah DKI Jakarta. Jakarta: Artikel KesehatanVol. 61. No. 11. Hal. 447-453

GLOBOCAN. Indonesia (2012) Estimated Cancer Mortality and Incidence All Ages : Female. [serial online]. Available from : URL : http://globocan.iarc.fr. Diunduh pada tanggal 10 Januari 2019

Harris S,Trevino A. P. 2015. Hubungan antara Faktor Sosio Ekonomi Ibu terhadap Pengetahuan Mengenai Tuberkulosis eJKI Vol. 3, No. 1, April 2015

Kemenkes RI. 2015. Panduan Program Nasional Gerakan Pencegahan dan Deteksi Dini Kanker Leher Rahim dan Kanker Payudara. Direktorat Pengendalian Penyakit Tidak Menular. Jakarta: Kemenkes RI.

Mimatun. N, Sifia L.B, 2013. Hubungan Antara Pengetahuan dan pendidikan dengan Pelaksanaan Deteksi Dini Kanker Serviks Melalui Iva. Jurnal Midpro 2013

Oktarisa K A, Puspita K D. 2016. Faktor-Faktor Yang Mempengaruhi Tingkat Pengetahuan Orang Tua Mengenai Kelainan Genetik Penyebab Disabilitas Intelektual Di Kota Semarang. Jurnal Kedokteran Diponegoro volume 5, Nomor 4, Oktober 2016 online : Http://EjournalS1.Undip.Ac.Id/Index.Php/Medicoissn Online : 2540-8844

Pristihana P W. 2013. Hubungan Tingkat Pendidikan Dengan Pengetahuan Ibu Rumah Tangga Tentang Pap Smear Di Desa Kauman Kecamatan Tangen Kabupaten Sragen. Skripsi Fakultas Kedokteran Universitas Muhammadiyah Surakarta.

Rini Rahmawati. 2010. Pengaruh Tingkat Pendidikan Formal WUS terhadap Pengetahuan Mengenai SADARI Sebagai Upaya Deteksi Dini Kanker Payudara di Kel. Patang Puluhan Kec. Wirobrajan Yogyakarta. Digital Library Fak Kedokteran UMY : http://FKUMY

Setiyowati Rahardjo Dan Erna Kusumawati. 2011. Hubungan Tingkat Pendidikan Dan Pengetahuan Dengan Perilaku Keluarga Sadar Gizi (Kadarzi) Pada Masyarakat Perkotaan Dan Perdesaan Di Kabupaten Banyumas. Jurnal Kesmasindo. Volume 4, Nomor 2, Juli 2011, Hlm. 150-158

Sulistiowati, Eva. 2014. Pengetahuan Tentang Faktor Risiko, Perilaku dan Deteksi Dini Kanker Serviks Dengan Inspeksi Visual Asam Asetat (IVA) Pada Wanita di Kecamatan Bogor Tengah. Bogor: Buletin Penelitian Kesehatan, Vol. 42. No. 3. Hal. 192-202

Wawan, A dan Dewi, M. 2011. Pengetahuan Sikap dan Perilaku Manusia. Yogyakarta: Nuha Medika 
Jurnal Kebidanan Indonesia. Vol 10 No 1. Januari 2019 (114-125)

Widiastuti, Y, Rahmawati, A., \& Purnamaningrum, Y.A. (2009). Kesehatan Reproduksi. Yogyakarta :Fitramaya

World Health Organization (WHO). 2013. Global Cancer Burden Rises TO 14.1 Million New Cases in 2012 : Marked increase in breasts cancers must be addressed. Switzerland : WHO 